\title{
The Synthesis of Novel Material 2,3-Dimethyl-2,3-dihydrofuro[3,4-b][1,4]dioxine-5,7-dicarboxylic acid
}

\author{
WANG Liping ${ }^{1, a}$, DENG Diandian ${ }^{1, b}$, YAN Hewei ${ }^{1, c}$, SUN Xiaoxia ${ }^{1, d^{*}}$, WEI \\ Chaochao $^{1, e}$
}

${ }^{1}$ Jiangxi Key Laboratory of Organic Chemistry, Jiangxi Science and Technology Normal University, Nanchang 330013, People's Republic of China

awangliping0520@126.com; ' dengdiandian11@126.com; ' ${ }^{\mathrm{b}}$ anhewei1990@163.com;

dsunxiaoxia77@126.com; ${ }^{e}$ weichaochao11@163.com;

Keywords:2,3-dimethyl-2,3-dihydrofuro[3,4-b][1,4]dioxine-5,7-dicarboxylic $\quad$ acid, organic light-emmitting material, synthesis, $\pi$-conjugated polymers

Abstract. A new synthetic approach to synthesize 2,3-dimethyl -2,3-dihydrofuro [3,4-b][1,4] dioxine-5,7 -dicarboxylic acid from a common precursor diglycolic acid was reported. Starting from the commercial material diethylene glycol, diethyl oxalate and 2,3-dibromobutane, the compound was synthesized through oxidation reaction, acylation, hydrolysis and elimination reaction with moderate yield via a five-step reaction. The procedure was described herein with several advantages, including high product yields and easy purification.

\section{Introduction}

Conjugated polymer materials as a new type of electroluminescent light, due to its potential application in terms of lighting, displays, etc., causing great concern in materials, chemical and industry. Compared with the currently widely used fluorescent lighting and LCD display, polymer light-emitting semiconductors (polymer light-emitting-diode, PLED) has low energy consumption, made the process simple, flexible, low cost, abundant light color and other characteristics, the market potential is huge $\mathrm{e}^{1-3}$. In recent years, organic conjugated small molecule compounds, and gradually become a hot research topic, these materials have molecular structure determination, synthesis controllable, reproducible material, monodisperse, stable glass state and a good film, these features make it can be used in organic electroluminescent devices promising material.

Over the past two decades the field of $\pi$-conjugated polymers has attracted the attention of many scientists due to the interesting electrical and optical properties of these compounds ${ }^{4-8}$. Since then, this field has expanded into an enormous research thrust, with applications in almost all aspects of energy storage, transmission, and conversion ${ }^{9-13}$.

Organic / polymeric semiconductor material information as a new generation of functional materials attracted the attention worldwide, more and more become the object of research institutions competing research and development. Developing the new synthetic strategies substituted monomers for the $\pi$-conjuated polymers is important and of urgent need. If we can further optimize the structure of conjugated polymers, molecules increase or decrease the orderly disorder to enhance carrier mobility will further enhance the photoelectric conversion efficiency of the polymer.

The study intends to synthesize 2,3-dimethyl -2,3-dihydrofuro[3,4-b][1,4]dioxine -5,7dicarboxylate and 2,3-dimethyl-2,3-dihydrofuro[3,4-b][1,4]dioxine-5,7-dicarboxylic acid two novel compounds, to synthesize new optoelectronic materials.

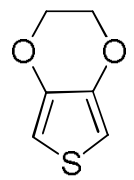

EDOT

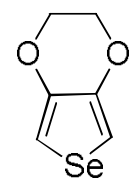

EDOS

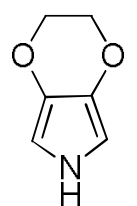

EDOPy

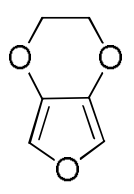

EDOF

Scheme 1 The structures of the materials 


\section{Experimental Section}

Characterization: ${ }^{1} \mathrm{H}$ NMR and ${ }^{13} \mathrm{C}$ NMR spectra were collected on a Bruker AM-400WB spectrometer in chloroform-d as solvent and tetramethylsilane (TMS) as the internal standard. The mass spectra were obtained by using a Bruker Daltonics Autoflex II TOF system.Materials: Diethyl ether and tetrahydrofuran (THF) were dried over sodium benzophenone and distilled under argon atmosphere before use. Toluene was dried over $\mathrm{CaH}_{2}$ and then distilled under nitrogen atmosphere and deoxygenated by purging with nitrogen for $30 \mathrm{~min}$ before use in monomer synthesis. 2,7-Dibromofluoren-9-one was purchased from Aldrich Chemical Co. and used without further purification. Other chemicals were purchased from Acros and used without further purification.

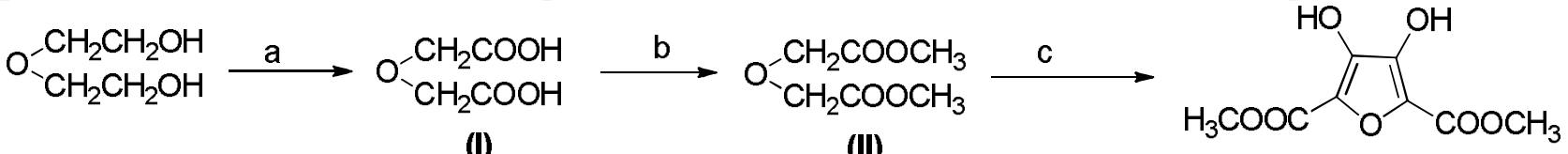

(I) (II)

(III)

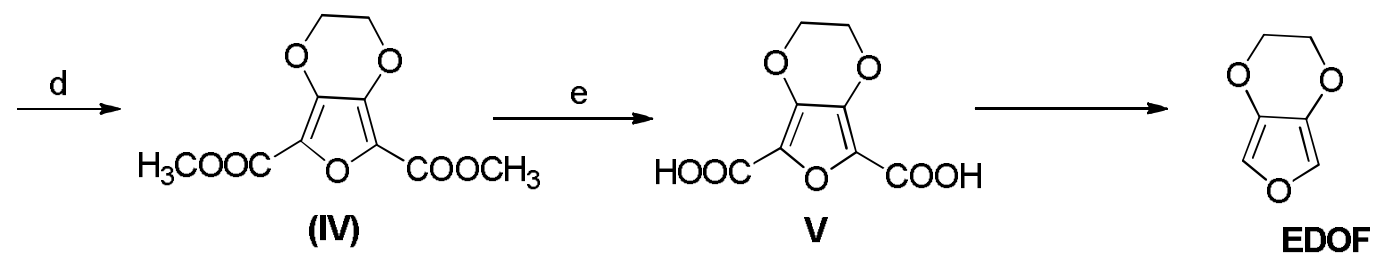

a) $\mathrm{HNO}_{3}, 90 \sim 100^{\circ} \mathrm{C}, 12 \mathrm{~h}$. b) $\mathrm{CH}_{3} \mathrm{OH}, \mathrm{SOCl}_{2} \mathrm{RT}, 24 \mathrm{~h}$. c) $\mathrm{CH}_{3} \mathrm{ONa}, \mathrm{CH}_{3} \mathrm{OH},(\mathrm{COOEt})_{2}, 70^{\circ} \mathrm{C}, 10 \mathrm{~h}$. d) $\mathrm{BrCH}_{2} \mathrm{CH}_{2} \mathrm{Br}, \mathrm{K}_{2} \mathrm{CO}_{3}$, DMF $110^{\circ} \mathrm{C}$, reflux 5h. e) $\mathrm{NaOH}$ ) Scheme 2 the sythesis of compound $\mathrm{V}$

\section{Synthesis of diethylene acetic (I)}

$100 \mathrm{~mL}$ of diethylene glycol was poured into a dry $2 \mathrm{~L}$ three-necked flask, then 1L $32 \%$ concentrated nitric acid was added to this mixture. The reaction solution was stirred for $8 \mathrm{~h}$ at $60{ }^{\circ} \mathrm{C}$. The excess of nitric acid was wiped off at $120^{\circ} \mathrm{C}$. The reaction mixture was poured into water and extracted by acetic ether. The organic layer separated and dried over anhydrous magnesium sulfite. The product was obtained as yellow solid. Yield: $90.2 \mathrm{~g},(64 \%) .{ }^{1} \mathrm{H}$ NMR (400 MHz, DMSO) $\delta 12.79$ (s, 2H), 4.09 (s, $4 \mathrm{H}) .{ }^{13} \mathrm{C} \mathrm{NMR}\left(100 \mathrm{MHz}, \mathrm{CDCl}_{3}\right): \delta 67.46,173.63$.

\section{Synthesis of dimethyl dimonophosphate(II)}

Diglycolic acid (10.0 g, $0.075 \mathrm{~mol})$ was added to a $250 \mathrm{ml}$ three-necked flask, then $\mathrm{SOCl}_{2}(21.6 \mathrm{ml}$, $0.30 \mathrm{~mol}$ ) was added dropwise. After dropping, after reacting at room temperature for 6 hours, $50 \mathrm{ml}$ of anhydrous methanol(10equiv) was slowly added dropwise in an ice bath. The reaction mixture was stirred for $8 \mathrm{~h}$ at room temperature.Evaporate the excess of $\mathrm{SOCl}_{2}$ and methanol, the residual liquid was extracted by ethyl acetate and neutralized by saturated solution of $\mathrm{NaHCO}_{3}$, the obtained organic phase was washed with water, dried over anhydrous $\mathrm{MgSO}_{4}$. The solvent was then removed by rotary evaporation to give a white solid (yield: $9.27 \mathrm{~g}, 76.3 \%$ ). ${ }^{1} \mathrm{H} \mathrm{NMR}\left(400 \mathrm{MHz}, \mathrm{CDCl}_{3}\right) \delta 4.26(\mathrm{~s}, 2 \mathrm{H})$, $3.78(\mathrm{~s}, 3 \mathrm{H}) .{ }^{13} \mathrm{C}$ NMR $\left(101 \mathrm{MHz}, \mathrm{CDCl}_{3}\right) \delta 170.11,68.12,51.99$.

\section{Synthesis of diethyl-3,4-dihydroxyfuran-2,5-dicarboxylate (III)}

$200 \mathrm{~mL}$ of anhydrous methanol was poured into a dry $500 \mathrm{~mL}$ three-necked flask, $\operatorname{sodium}(2.13 \mathrm{~g}, 0.09$ mol) was added slowly. Then the dimethyl 2,2'-oxydiacetate (10.00 g,0.06 mol) and he diethyl oxalate $(6.76 \mathrm{~g}, 0.05 \mathrm{~mol})$ was slowly added and then stirred for $3 \mathrm{~h} 75^{\circ} \mathrm{C}$. A great deal of yellow solid was precipitated, and washed with ethanol, then added slowly hydrochloric acid. The product was ${ }^{1} \mathrm{H}$ NMR (400 MHz, DMSO) $\delta 3.70$ (s, 6H) ${ }^{13} \mathrm{C}$ NMR (10 MHz, DMSO) $\delta$ 158.98, 144.14, 127.84, 51.80; LRMS (ESI-) $\mathrm{M} / \mathrm{z}$ calcd for $\mathrm{C}_{8} \mathrm{H}_{8} \mathrm{O}_{7}$. [M-H] 215.1; found 2015.2. 


\section{Synthesis of 2,3-dimethyl-2,3-dihydrofuro[3,4-b][1,4]dioxine-5,7-dicarboxylate (IV)}

Diethyl-3,4-dihydroxyfuran-2,5-dicarboxylate $(0.2 \mathrm{~g}, 0.9 \mathrm{mmol})$, dry potassium carbonate $(0.26 \mathrm{~g}, 1.8$ mmol) were dissolved in $\operatorname{DMF}(25 \mathrm{ml})$ and stirred for $30 \mathrm{~min}$ at $110^{\circ} \mathrm{C}$. 2,3-dibromobutane $(0.4 \mathrm{~g}, 1.8$ mmol) was added to reaction system dropwisely and then stirred for $8 \mathrm{~h}$ at $110^{\circ} \mathrm{C}$. The reaction mixture was poured into water, filtered to get a white solid $0.14 \mathrm{~g}(56 \%) .{ }^{1} \mathrm{H} \mathrm{NMR}\left(400 \mathrm{MHz}, \mathrm{CDCl}_{3}\right)$ $\delta 4.45(\mathrm{~d}, J=6.6 \mathrm{~Hz}, 1 \mathrm{H}), 4.08(\mathrm{~s}, 1 \mathrm{H}), 3.90(\mathrm{~s}, 6 \mathrm{H}), 1.42(\mathrm{dd}, J=28.8,5.4 \mathrm{~Hz}, 6 \mathrm{H}) .{ }^{13} \mathrm{C}$ NMR $(101$ $\left.\mathrm{MHz}, \mathrm{CDCl}_{3}\right) \delta 158.26,140.69,139.98,126.70,74.54,51.96,16.97 . \mathrm{M} / \mathrm{z}$ calcd for $\mathrm{C}_{12} \mathrm{H}_{14} \mathrm{O}_{7}$. $[\mathrm{M}+\mathrm{Na}]^{+}$293.0; found 293.1.

\section{Synthesis of 2,3-dimethyl-2,3-dihydrofuro[3,4-b][1,4]dioxine-5,7-dicarboxylic acid (V)}

2,3-dimethyl-2,3-dihydrofuro[3,4-b][1,4]dioxine-5,7-dicarboxylate $(0.5 \mathrm{~g}, 1.8 \mathrm{mmol})$ and sodium hydroxide solution $(0.7 \mathrm{~g}, 18 \mathrm{mmol})$ were dissolved in $10 \mathrm{ml}$ water and stirred for $8 \mathrm{~min}$ at $60^{\circ} \mathrm{C}$. This mixture was washed three times with dichloromethane, and added drop by drop dilute hydrochloric acid until no precipitation. The white solid was separated by filtration, and the yield is $0.32 \mathrm{~g}(74 \%)$.

${ }^{1} \mathrm{H}$ NMR (400 MHz, DMSO) $\delta 13.21(\mathrm{~s}, 2 \mathrm{H}), 4.51(\mathrm{q}, J=6.2 \mathrm{~Hz}, 1 \mathrm{H}), 4.14(\mathrm{~d}, J=4.2 \mathrm{~Hz}, 1 \mathrm{H}), 1.32$ $(\mathrm{d}, J=5.7 \mathrm{~Hz}, 3 \mathrm{H}), 1.24$ (d, $J=6.5 \mathrm{~Hz}, 3 \mathrm{H}) .{ }^{13} \mathrm{C}$ NMR (101 MHz, DMSO) $\delta 158.01,139.54,138.78$, 75.23, 73.13, 16.96, 13.30; LRMS (ESI+): M/z calcd for $\mathrm{C}_{10} \mathrm{H}_{10} \mathrm{O}_{7}$. [M+Na $]^{+}$265.0; found 265.1.

\section{Results and Discussion}

In this study we efficiently synthesized the target product by five-step, such as the oxidation of diethylene glycol, di-acylated Gly, furan ring, Williamson, reaction, hydrolysis of the ester, etc. In the synthesis of diethyl-3,4-dihydroxyfuran-2,5-dicarboxylate, taking into account the instability of the previous step, the yield is low, I made some appropriate adjustments in the experimental procedure, such as change the amount of diethyl oxalate, reaction time was changed and in processing, rinse solid with anhydrous ethanol. The target product have Narrow band gap, wide spectral absorption properties of high electron affinity and low ionization energy, high migration rate of nature. It is a good photoelectric materials.

\section{Summary}

In conclusion, we have developed and optimized an efficient for the synthesis of 2,3-dimethyl-2,3 -dihydrofuro[3,4-b][1,4]dioxine-5,7-dicarboxylic acid from the commercially viable ethylene diglycol. The procedure described herein offers several advantages, including moderate product yields, easy purification, and large scale production. Furthermore, this method is a useful addition to the present methodology for the synthesis of this class of compounds.

\section{Acknowledgements}

We are grateful for the financial support of the National Natural Science Foundation of China (No.21462018), the Science Fund of the Technology Office of Jiangxi, China (2009ZDS11100 and 20132BBE50024).

\section{References}

[1] Yu, G.; Gao, J.; Hummelen, J. C.; Wudl, F.; Heeger, A. J. Science 1995, 270, 1789.

[2] Chen, H.-Y.; Zhang, S.; Li, G.; Yang, Y. J. Am. Chem. Soc. 2008, 130, 16144.

[3] Turbiez, M.; Janssen, R. A. J. Adv. Mater. 2008, 20, 2556.

[4] Xu, J., Hou, J.; Zhang, S.; Nie, G.; Pu, S.; Shen, L.;Xiao, Q. J. Electroanal. Chem. 2005, 578, 345.

[5] Nalwa, H. S., Ed.; John Wiley \& Sons: Chichester, England 1997, Vol. 1-4. 
[6] Feast, W. J., Tsibouklis, J., Pouwer, K. L., Groenendaal, L., Meijer, E. W. Polymer, 1996, 37, 5017.

[7] Stenger-Smith, J. D. Prog. Polym. Sci. 1998, 23, 57.

[8] Epstein, A. J., Yang, Y., Guest Eds. MRS Bull. 1997, 22 (6), 13-62.

[9] Aqad, E., Lakshmikantham, M. V., Cava, M. P. Org. Lett. 2001, 3, 4283-4285.

[10]Heeney M., Zhang W.I., Skabara P. J., Sparrowe D. Tierney, S. Chem. Commun. 2007, 50615063.

[11]Patra A., Wijsboom Y. H., Zade S. S., Li M., Sheynin Y., Leitus G., Bendikov M. J. Am. Chem. Soc. 2008, 130, 6734-6736.

[12] Das S., Zade, S. S. Chem. Commun. 2010, 46, 1168-1170.

[13]Schumacher R. F., Rosario A. R., Souza A. C. G., Menezes P. H., Zeni G. Org. Lett. 2010, 12, 1952-1955. 